\title{
REFLEXÕES SOBRE CULTURA E DESENVOLVIMENTO: CELSO FURTADO, DOUGLASS NORTH E AMARTYA SEN
}

\section{Eduardo José Monteiro da Costa 1 Luiz Alberto de Souza Aranha Machado}

\section{Introdução}

Celso Furtado e Douglass North, se vivos estivessem, completariam 100 anos em 2020. Ambos foram autores de vasta produção intelectual que se notabilizaram por estudarem os elementos determinantes do desenvolvimento, ainda que com bases em perspectivas teóricas diferentes.

Furtado, antecipou em algumas décadas a inclusão da questão cultural como elemento importante para a análise econômica. Se atualmente questões relacionadas ao desenvolvimento (ou ao subdesenvolvimento) são mais amplamente debatidas, indiscutivelmente isso se deve, em parte, a sua militância (insistência) intelectual. A importância de sua produção intelectual é tamanha, sobretudo para a formação do pensamento econômico brasileiro e latino-americano, que alguns consideram o fato dele não ter sido laureado com o Prêmio Nobel de Economia uma das maiores injustiças proporcionadas pelo mundo acadêmico.

North, por seu turno, também incorporou a análise da cultura como a chave para a compreensão da dependência de trajetória dos países. E, em função de suas contribuições no campo da historiografia, desenvolvimento e teoria econômica, por meio da formulação de seus conceitos analíticos relacionados a teoria das instituições e da mudança institucional, foi laureado no ano de 1993 com o Prêmio Nobel de Economia.

Porém, com o objetivo de alargar um pouco mais este instigante e necessário debate, subsidiando reflexões contemporâneas, optamos por estender referida homenagem a mais um importante e diferenciado economista, Amartya Sen, que também se deteve na análise da problemática do desenvolvimento incorporando a cultura como elemento analítico importante; e, que, em função de suas contribuições, também, acabou laureado com o Prêmio Nobel de Economia em 1998.

Assim, em um momento no qual diversas escolas de pensamento estão "redescobrindo" a importância da cultura para a análise do desenvolvimento, o resgate das formulações seminais destes três importantes intérpretes do desenvolvimento se torna mais do que oportuno.

\footnotetext{
${ }^{1}$ Doutor em Economia pela Unicamp e professor da Faculdade de Economia e do Programa de Pós-Graduação em Gestão Pública do Núcleo de Altos Estudos da Amazônia (PPGGP/NAEA), ambos da UFPA. Correio eletrônico: ejmcufpa@gmail.com

2 Mestre em Criatividade e Inovação pela Universidade Fernando Pessoa (Portugal) e Diretor Adjunto do Instituto Fernand Braudel de Economia Mundial. Correio eletrônico: lasam.machado@gmail.com
} 
Desta forma, este ensaio, após esta breve introdução, divide-se em quatro partes. Nas três partes seguintes é feito um compêndio dos principais apontamentos de Celso Furtado, Douglass North e Amartya Sen sobre a temática do desenvolvimento e cultura, precedidos de uma rápida biografia de cada autor. Finalmente, a parte conclusiva é reservada para uma breve síntese relacionando aquilo que se apresenta como pontos de convergência ou complementariedade analíticos.

\section{Celso Furtado}

\subsection{Síntese biográfica}

Nascido em Pombal, sertão da Paraíba, no dia 26 de julho de 1920, Celso Furtado fez os estudos secundários no Liceu Paraibano e no Ginásio Pernambucano do Recife. Passou a sua infância e juventude no Nordeste, tornando-se conhecedor de uma realidade pela qual manteve forte interesse ao longo da vida. Transferindo-se em 1939 para o Rio de Janeiro, entrou para a Faculdade de Direito, formando-se, em 1944, pela então Universidade do Brasil (Rio de Janeiro). Após a conclusão do curso, foi convocado para a Força Expedicionária Brasileira. Com a patente de aspirante a oficial, seguiu para a Itália, onde serviu na Toscana como oficial de ligação junto ao V Exército Norte-Americano.

No período pós-guerra foi agraciado com o Prêmio Franklin D. Roosevelt, do Instituto Brasil-Estados Unidos com o ensaio Trajetória da Democracia na América. Viajou para a França, onde se inscreveu no curso de doutoramento em Economia da Universidade de Paris-Sorbonne e no Instituto de Ciências Políticas, onde pôde presenciar o esforço de reconstrução da Europa com o Plano Marshall, e a importância que naquela altura assumia o Estado como indutor do desenvolvimento. Foi também fortemente influenciado pelas ideias seminais de François Perroux, sobretudo o conceito de macrodecisão e de que o desenvolvimento poderia ser induzido por meio de ações do Estado resultantes de decisões políticas. Tornou-se doutor em Economia em 1948 pela Universidade de Paris, com a tese L'économie coloniale bresilienne, sob a orientação de Maurice Byé.

De volta ao Brasil, retoma o trabalho no Departamento Administrativo do Serviço Público (DASP), em que fora aprovado em concurso em 1943, juntando-se ao quadro de economistas da Fundação Getúlio Vargas, trabalhando na revista Conjuntura Econômica.

Em 1949 transfere-se para Santiago do Chile, passando a integrar, sob o comando do economista argentino Raúl Prebisch, o corpo de cientistas sociais da recém-criada Comissão Econômica das Nações Unidas para a América Latina e Caribe (Cepal/ONU), organismo que 
acabaria se tornando, sob a batuta dos dois, de acordo com Brandão (2008, p. 66), "[...] o grande intelectual orgânico - teórico, dirigente político, realizador de uma reforma intelectual e moral do desenvolvimento e do desenvolvimentismo na América Latina."

Ainda como funcionário da ONU e de volta ao Brasil, chefiou o Grupo Misto Cepal-BNDE durante o segundo Governo Vargas, dirigiu a revista Econômica Brasileira (que reuniu a primeira geração de economistas de esquerda do País), elaborou durante o governo de Juscelino Kubistchek o Plano de Desenvolvimento do Nordeste, que iria dar origem à Sudene, e foi ministro do Planejamento do governo João Goulart, para o qual elaborou o Plano Trienal; tentativa malsucedida de conter a crescente inflação, assegurar o crescimento e criar condições políticas para a sobrevivência do regime democrático.

Com os direitos políticos cassados pelo regime militar que assumiu o poder em 1964, foi para o exílio, concentrando forças na vida acadêmica, primeiro em Yale e, depois, por mais de uma década, na Sorbonne, sem jamais perder o interesse pela política e pela economia do Brasil e da América Latina.

Com a anistia e a redemocratização, voltou ao Brasil e assumiu em 1985 o Ministério da Cultura do governo José Sarney. ${ }^{3}$ Concluído seu mandato à frente do Ministério, Furtado continuou, ao longo da década de 1990 e até sua morte em 2004, produzindo ativamente, conforme Brandão (2008, p. 67) "[...] em franca rota de colisão intelectual com a opção civilizacional e a política econômica hegemônica no País".

Em setembro de 2001, Celso Furtado foi eleito por aclamação "Economista Emérito do Brasil", na plenária final do Congresso Brasileiro de Economia, realizado em Recife. Em 2003, por ocasião de um seminário internacional promovido pela rede da Unesco sobre economia global e desenvolvimento sustentável, a Cátedra e a Rede da Unesco e da Universidade das Nações Unidas (REGGEN), a Associação de Economistas da América Latina (AEALC) e 0 Conselho Latino-Americano de Ciências Sociais (CLACSO) apresentaram o nome de Celso Furtado como candidato ao Prêmio Nobel de Economia em 2004. Em janeiro de 2004, os documentos foram formalmente enviados à Academia de Ciências da Suécia. Para frustração dos brasileiros, que jamais tiveram a oportunidade de comemorar a concessão de um Prêmio Nobel a algum conterrâneo, Furtado não foi escolhido; tendo o Prêmio Nobel de Economia daquele ano sido dividido por Finn Kydland e Edward Prescott, por suas contribuições à

\footnotetext{
${ }^{3}$ De acordo com Brandão (2008, p. 67), "[...] cargo que era ao mesmo tempo a reparação de uma injustiça - 0 truncamento de sua vocação de homem do Estado -, o reconhecimento de sua grandeza intelectual e a manifestação de sua perda de influência no debate e na determinação dos rumos da economia".
} 
macroeconomia dinâmica, em decorrência de seus estudos sobre a consistência temporal da política econômica e as forças motrizes por trás dos ciclos de negócios.

\subsection{Desenvolvimento}

Reconhecido e consagrado como economista, Celso Furtado manifestou desde cedo sua visão do desenvolvimento não como um processo limitado às variações econômicas, mas como parte de algo muito mais amplo. Sem jamais perder de vista a realidade do Brasil - e do Nordeste, sua região de origem, em particular - Furtado procurou observar a realidade nacional por meio do entendimento racional proporcionado pela ciência de um modo geral (histórica, econômica, política, social) como parte inicial do projeto de mudança, entendida sempre como um desejo de constante aperfeiçoamento.

Desta forma, o pensamento estruturalista de Furtado assinala que o processo histórico que conduziu ao desenvolvimento através do capitalismo engendrou seu revés, países imersos no sistema, mas carentes de desenvolvimento. O dinamismo capitalista produziu 0 desenvolvimento no seu centro difusor, porém, em certas regiões periféricas que foram irradiadas por ele, estabeleceu-se outro processo, que não teve a mesma forma, nem compartilhou dos mesmos efeitos. A falta de desenvolvimento dos países que estão à margem do centro capitalista, mas complementares à realização do sistema, foi denominada de subdesenvolvimento. Desenvolvimento e subdesenvolvimento são, portanto, formações coetâneas que jamais podem ser entendidas como resultado de uma etapa.

Ou seja, contrariando a visão etapista do desenvolvimento econômico, desenvolvimento e subdesenvolvimento são situações históricas distintas, porém derivadas de um mesmo impulso inicial - faces de uma mesma dinâmica - com o subdesenvolvimento se constituindo num processo histórico autônomo e heterogêneo ${ }^{4}$ de conformação estrutural produzido pela forma como se propagou o progresso tecnológico ${ }^{5}$ no plano internacional, e derivado de malformações sociais e econômicas durante o processo de difusão do sistema capitalista na periferia. Toda

\footnotetext{
${ }^{4}$ De acordo com a teoria desenvolvida por Celso Furtado em suas diversas obras, o subdesenvolvimento não se constitui enquanto fenômeno homogêneo. 0 próprio subdesenvolvimento é heterogêneo do ponto de vista estrutural, apresentando-se sob várias formas em diferentes estágios, inclusive com uma fase superior em que existe um núcleo industrial diversificado.

50 termo progresso tecnológico é uma expressão genérica que no seu uso corrente engloba todas as transformações sociais que possibilitam a persistência do processo de acumulação capitalista. Manifesta-se sob a forma de processos produtivos mais eficazes e também de novos produtos que são a face exterior da civilização (Furtado, 1992b). Segundo Furtado, como o progresso tecnológico ocorre de forma pontual no espaço, não se difundindo, a região detentora deste avanço passa a lograr efeitos positivos decorrentes de toda uma gama de consequências oriundas da introdução desta nova tecnologia (Furtado, 1998).
} 
economia subdesenvolvida é, portanto, necessariamente dependente e periférica, pois o subdesenvolvimento é uma criação da situação de dependência e um desequilíbrio na assimilação dos avanços tecnológicos produzidos pelo capitalismo industrial a favor das inovações que incidem diretamente sobre o estilo de vida.

Posto que o subdesenvolvimento surge de uma assimetria estrutural nas relações da periferia com o núcleo do sistema, a sua tomada de consciência esclarece as limitações impostas à nação, ou região, pelo caráter da divisão internacional do trabalho existente e por esta estrutura socioeconômica que tende a se perpetuar em função de elementos: ${ }^{6}$ da matriz institucional pré-existente, orientada para a divisão da riqueza e da renda; das condições históricas ligadas à emergência do sistema de divisão internacional do trabalho; do aumento da taxa de exploração dos países pobres e do uso do excedente adicional pelas elites, para financiamento de seu consumo mimético, de que resulta uma ruptura cultural que se manifesta através do processo de modernização; da orientação do crescimento em função dos interesses da minoria "modernizada"; do custo ascendente da tecnologia requerida para acompanhar por meio da produção local os padrões de consumo dos países avançados, o que, por seu lado, facilita a penetração das grandes empresas de ação internacional; e, da necessidade de fazer face aos custos crescentes em moeda estrangeira de produção destinada ao mercado interno, abrindo o caminho à exportação de mão-de-obra barata sob o disfarce de produtos manufaturados.

Em função de tudo isso, o subdesenvolvimento de uma sociedade acaba sendo sempre a expressão de um insuficiente nível de racionalidade pública e social. Desta forma, a sua superação somente pode ser concebida no quadro de um projeto político transescalar, articulado e coordenado pelo Estado enquanto centro nacional de decisão válido, capaz de subordinar os interesses individuais aos interesses regionais e nacionais coletivos buscados a médio e longo prazo através do planejamento do desenvolvimento, fundamentados, sempre, numa clara compreensão da estrutura socioeconômica e espacial da região objeto, e na superação da situação de dependência e exploração. Implica, portanto, na tentativa de encontrar resposta a múltiplas questões. Em primeiro lugar, apresentam-se as exigências de um processo de mundialização, imposto pela lógica dos mercados, que está na base da difusão da civilização industrial. Em segundo lugar, configuram-se os requerimentos de uma tecnologia que é fruto da história das economias centrais e que continua a ser gerada em função dos problemas com que estas se defrontam. E, finalmente, estão as especificidades das formas sociais mais aptas para

6 Ver: Furtado (1983; 1992b; 1998). 
operar essa tecnologia, ou seja, as formas de organização da produção e de incitação ao trabalho.

A partir desta constatação, Celso Furtado destaca a importância das macrodecisões enquanto objeto de vontade política na transformação das estruturas regionais subdesenvolvidas, afirmando que mais do que transformação, o desenvolvimento é invenção na medida em que comporta um elemento de intencionalidade. Segundo seu arcabouço teórico 0 sistema econômico, seja este local, regional ou mesmo nacional, significa a existência de dispositivos de coordenação e certa unidade de propósitos e comando, com intervenções de centros de decisão, que representam a estrutura de poder, e que respondem por ideais sociais, políticos e econômicos. Há, portanto, nesta estrutura, um quadro institucional e um poder regulador, fundado na coação e/ou consentimento, capaz de arbitrar os conflitos que se manifestam em torno da apropriação e da alocação dos escassos recursos. Consequentemente, o entendimento do comportamento dos agentes econômicos somente é possível através da análise de como estão arquitetadas as suas estruturas sociais - uma análise que permite 0 estabelecimento de uma ponte com a teoria das instituições de North.

Desta maneira, qualquer tentativa de superação do subdesenvolvimento deve estar assentada num projeto político, fundado em percuciente conhecimento da realidade e esposado por amplos segmentos sociais, ${ }^{7}$ que aumente o poder regulador das atividades econômicas, única forma de colocá-las a serviço da satisfação das necessidades sociais legitimamente conhecidas, e capaz de romper com o quadro de dependência estrutural de uma economia periférica. Nesta construção, Furtado é enfático ao colocar que qualquer concepção de desenvolvimento não pode alienar-se de sua estrutura social, e nem tampouco a formulação de uma estratégia desenvolvimentista pode ser concebida sem preparação ideológica. Este processo deve estar ancorado à ideia de um projeto nacional que recupere o mercado interno como centro dinâmico da economia, reforme as estruturas anacrônicas que pesam sobre a sociedade e comprometem sua estabilidade, e resista às forças que operam no sentido da desarticulação do sistema econômico nacional e que ameaçam a unidade federativa. ${ }^{8}$

Isto pressupõe o exercício de uma vontade política apoiada num amplo consenso social e num projeto nacional tendo em vista sempre que o desenvolvimento econômico precisa ser

\footnotetext{
${ }^{7}$ Segundo Furtado (1992b), um dos traços mais significativos de uma sociedade subdesenvolvida é a exclusão de importantes segmentos de população da atividade política, privados que estão de recursos de poder. Esta situação somente se modifica com a emergência de formas alternativas de organização social capazes de ativar os segmentos de população politicamente inertes.

8 Ver: Furtado (1980; 1992a; 1992b).
} 
entendido como um processo dinâmico que transcende aspectos de natureza puramente econômica, alcançando toda a estrutura de organização da sociedade, comportando sempre um elemento de invenção. É um processo autônomo, sustentado e civilizador, baseado no progresso tecnológico e manifesto numa estrutura de sociedade mais adiantada, englobando aspectos culturais, institucionais, sociais e econômicos, que alargam os horizontes de possibilidades dos agentes e que conduzem a acumulação capitalista à criação de valores, bens e serviços que se difundem mais homogeneamente pela coletividade. ${ }^{9}$ Em última instância, implica na ampliação da liberdade em todas as esferas da vida e da sociedade.

Neste sentido, na sua morfogênese, o desenvolvimento necessita desobstruir as forças que tencionam pela manutenção das estruturas tradicionais de dominação e reprodução do poder, requerendo, portanto, ser implantado e coordenado por uma unidade dominante possuidora de poder, força e coação. Possui inerentemente dois aspectos peculiares: um mais atraente, próprio de um processo de arranjo, montagem, dar sentido, direção, coerência às transformações que uma sociedade quer armar e projetar para o futuro, dispondo de certos instrumentos eleitos para determinados fins; e aquele menos atraente, próprio dos processos de se desmontar, desarranjar, importunar, constranger, frustrar expectativas e ações deletérias à construção social.

\subsection{Cultura}

Embora a ênfase de Furtado na estreita relação entre cultura e desenvolvimento tenha se acentuado a partir da década de 1970 - ganhando ainda mais destaque quando tornou-se ministro da Cultura no governo de José Sarney na década seguinte -, a sua preocupação com 0 vínculo entre cultura e economia (e, por extensão, o desenvolvimento), é muito anterior. Ou seja, é parte indissociável na análise interdisciplinar do (sub)desenvolvimento brasileiro; que, por sua vez, origina-se de uma abordagem histórico-estrutural, na qual não apenas se percebe os fortes laços entre cultura e economia, mas, também, com os conceitos de desenvolvimento, criatividade e dependência.

Na perspectiva de Brandão (2008, p. 69), as principais características da elaboração furtadiana são:

\footnotetext{
${ }^{9}$ Na visão de Furtado (1992b) a busca pela homogeneização social não significa uniformização dos padrões de vida, e sim a que membros de uma sociedade satisfaçam de forma apropriada às necessidades de alimentação, vestuário, moradia, acesso à educação, ao lazer e a um mínimo de bens culturais.
} 
a) o tratamento da economia pelo método-histórico-estrutural, violentando o mainstream da disciplina; b) a historicização do estruturalismo latino-americano, especialmente das teorias originariamente defendidas por Raúl Prebisch; c) a crítica à teoria ricardiana das vantagens comparativas no comércio internacional; d) a percepção de que o mercado, não só na América Latina, mas, em geral, é uma entidade incapaz de se autorregular, o que torna inevitável e necessária a intervenção planejadora do Estado; e) a hipótese de que o subdesenvolvimento não é um estágio que todas as sociedades têm que percorrer no seu caminho para o desenvolvimento, mas um processo qualitativamente distinto da experiência dos países centrais e um produto necessário, tanto quanto o desenvolvimento, do processo de expansão da economia capitalista mundial; f) a percepção de que a heterogeneidade estrutural e o dualismo dos países dependentes e produtos da expansão europeia como o nosso, reproduzem também no plano doméstico a assimetria entre centro industrializado e periferia explorada, hiato capaz de pôr em risco a unidade de ação.

Neste diapasão, os países periféricos (subdesenvolvidos), dependentes dos países centrais (desenvolvidos), são submetidos a uma exploração crescente, que reforça cada vez mais essa conexão entre dependência e exploração; a ponto de se constituir num ciclo de retroalimentação sistemática. Esse ciclo de dependência e exploração acaba se perpetuando por meio de três dimensões: econômica, política e cultural.

A dimensão econômica pode ser, por sua vez, subdividida em: comercial, financeira e tecnológica.

(i) A comercial, decorre das relações entre países centrais e periféricos resultante da divisão internacional do trabalho. Nela, os países centrais especializaram-se na produção de bens de consumo duráveis e de bens de capital, enquanto que os países periféricos na produção de bens primários, em especial, alimentos e matérias-primas. Como os preços desses produtos evoluem de forma assimétrica, os países periféricos foram sendo obrigados a produzir (e exportar) quantidades cada vez maiores de bens primários para continuar a importar o mesmo volume de bens de consumo duráveis e de bens de capital. Tal situação, ao se estender no tempo por longos períodos, constitui-se num processo de transferência de riqueza dos países periféricos para os centrais. Esse mecanismo, que é o ponto alto da interpretação dependentista, tornou-se conhecido como "deterioração dos termos de intercâmbio" ou "deterioração das relações de trocas".

(ii) A financeira se explica pela transferência de recursos em direção aos países centrais por meio do pagamento de royalties, das remessas de lucros das empresas multinacionais e do pagamento de elevado montante de juros (onerando pesadamente a balança de serviços).

(iii) A tecnológica pode ser explicada pelo atrelamento dos países periféricos à tecnologia desenvolvida nos países centrais. Ou seja, além de não desenvolverem tecnologias próprias, os países periféricos acabam muitas vezes utilizando máquinas e equipamentos tecnologicamente já superados nos países centrais, pelo quais ainda pagam royalties por sua utilização. 
A dimensão política, por seu turno, tem na internacionalização dos centros de decisão a sua face mais visível. Pressionados pelo ciclo de exploração e dependência, os países periféricos acabam se tornando excessivamente vulneráveis, o que faz com que muitas das decisões políticas adotadas não reflitam necessariamente o ponto de vista da maior parte de suas respectivas populações, mas um alinhamento de suas elites com os interesses internacionais. Tal fenômeno pode ser observado tanto na política interna como na política internacional, quando a posição desses países é fortemente influenciada pelos países centrais por ocasião de tomadas de decisão em organismos multilaterais como a ONU, a OMC ou o FMI.

Por fim, a dimensão cultural pode ser explicada pela assimilação dos valores, hábitos, ideais e comportamentos dos países centrais por parte das populações e das elites dos países periféricos; influência acentuada pelo desenvolvimento da telemática, que envolve os avanços tecnológicos no campo da microeletrônica e telecomunicações.

No que se refere à relevância da criatividade, Alfredo Bosi afirma no Prefácio de Criatividade e dependência na civilização industrial:

\begin{abstract}
A história das culturas mostra a emergência, em determinados lugares e tempos, de obras de arte e pensamento tão belas e complexas que resistiram aos séculos e ainda hoje encantam e ensinam, apesar das distâncias às vezes milenares e das diferenças de estilo de vida e concepção de mundo. A palavra-chave para Celso Furtado passa a ser "criatividade". É nesse conceito que se apoia a sua admiração pela tragédia ática, pela historiografia de Heródoto, pela filosofia dos pré-socráticos, pela escavação moral e religiosa dos hindus, em suma, pela ciência, pela arte e pela filosofia criadas em sociedades de baixo excedente econômico (Furtado, 2008, p. 23).
\end{abstract}

O reconhecimento da criatividade como pré-requisito da inventividade humana faz de Furtado um precursor, de certa forma, de autores que se consagraram internacionalmente décadas depois como grandes especialistas em inovação, entre os quais Porter (1989) e Christensen (2001), ou mesmo da Economia Criativa, uma nova linha de pesquisa que surgiu na transição para o século XXI. ${ }^{10}$

Nessa perspectiva, complementa Furtado (2008, p. 112):

A gama maravilhosa de culturas que já surgiram sobre a Terra testemunha o fabuloso potencial de inventividade do homem. Se algo sabemos do processo de criatividade cultural, é exatamente que as potencialidades do homem são insondáveis: em níveis de acumulação que hoje nos parecem extremamente baixos produziram-se civilizações que, em muitos aspectos, não foram superadas.

\footnotetext{
${ }^{10}$ Aliás, é no livro Criatividade e dependência na sociedade industrial que a então secretária Cláudia Leitão foi buscar a epígrafe do Plano da Secretaria de Economia Criativa, apresentado à nação em 2011: "Quaisquer que sejam as antinomias que se apresentem entre as visões da história que emergem em uma sociedade, o processo de mudança social que chamamos desenvolvimento adquire certa nitidez quando o relacionamos com a ideia de criatividade" (Furtado, 2008, p. 11).
} 
Frente a tamanha admiração pelas genuínas manifestações culturais decorrentes da criatividade humana, não é motivo de surpresa a decepção manifesta por Furtado em obras mais recentes diante da homogeneização cultural representada pelo predomínio dos padrões de consumo - moda, música, costumes e hábitos - típicos de populações de nações desenvolvidas ocidentais, em especial da norte-americana, por parte das populações dos países subdesenvolvidos. ${ }^{11}$

Para fechar esta seção, julgamos mais do que oportuno mencionar o alerta feito por Furtado diante dos desafios impostos pelo vertiginoso ritmo das mudanças que caracteriza a economia globalizada.

$\mathrm{Na}$ fase em que nos encontramos, de explosão dos meios de comunicação, o processo de globalização do sistema de cultura terá que ser cada vez mais rápido, tudo nos leva a crer que estamos fechando o ciclo que se abriu no século XVI. Todos os povos lutam para ter acesso ao patrimônio cultural comum da humanidade, o qual se enriquece permanentemente. Resta saber quais serão os povos que continuarão a contribuir para esse enriquecimento e quais aqueles que serão relegados ao papel passivo de simples consumidores de bens culturais adquiridos nos mercados. Ter ou não ter direito à criatividade, eis a questão (Furtado, 1984, p. 25).

\section{Douglass North}

\subsection{Síntese biográfica}

Nascido em Cambridge, Massachusetts, no ano de 1920, Douglass North obteve o seu doutorado em economia na Universidade da Califórnia em Berkeley em 1952. Lecionou na Universidade do Estado de Washington em Seattle de 1950 a 1983, quando assumiu a titularidade da cátedra Henry R. Luce of Law and Liberty do Departamento de Economia da Universidade Washington, em St. Louis, Missouri, a ocupando até o seu falecimento em novembro de 2015 aos 95 anos.

Desde cedo North demonstrou interesse pelos estudos na área de história econômica, sendo um dos pioneiros nos Estados Unidos a aplicar o instrumental analítico neoclássico com o uso de métodos quantitativos para a análise da historiografia econômica. Por isso é considerado um dos precursores da Nova Escola Histórica. Na década de 1980 rompe progressivamente com este escopo analítico ao introduzir as instituições como elemento analítico importante para a análise do desenvolvimento em uma perspectiva teórica e histórica, tornando-se um dos maiores

\footnotetext{
11 Silva e Barros (2014, p. 19) assinalam a respeito desse fenômeno: "Esse movimento teórico iniciado nos anos setenta tem como tela de fundo 0 avanço da industrialização em um quadro de desenvolvimento imitativo, característico de uma sociedade que pretende reproduzir a cultura material do capitalismo avançado privando a grande maioria da população de bens e serviços essenciais. Nesse contexto, a situação de subdesenvolvimento latino-americano passa a ser percebida como resultado da discrepância entre as sofisticadas exigências de modernização das classes dominantes e precariedade do grau de desenvolvimento das forças produtivas."
} 
expoentes da Nova Economia Institucional, e, em decorrência disto, acabou laureado no ano de 1993 com o Prêmio Nobel de Economia.

Ao longo de sua vida, North visitou o Brasil algumas vezes. Numa delas, em 1961, teve oportunidade de encontrar-se com Celso Furtado, com quem possui interessantes paralelos biográficos. ${ }^{12}$ Ambos nasceram em 1920, lutaram na Segunda Guerra (Furtado na Europa, North no Pacífico) e publicaram em pouco espaço de tempo obras seminais sobre a história econômica de seus respectivos países: Furtado (Formação Econômica do Brasil) e North (The Economic Growth of the United States, 1790-1860).

A visita de North ao Brasil se deu no contexto da Guerra Fria e suas repercussões na América Latina, no período entre o lançamento pelo presidente dos Estado Unidos, J. F. Kennedy, da proposta da "Aliança para o Progresso" no mês de março em Washington e seu início oficial na Conferência de Punta del Este em agosto de 1961. A agitação político-social, especialmente em Pernambuco por causa das Ligas Camponesas, e a pobreza no nordeste brasileiro atraíram a atenção dos Estados Unidos. Assim, o acordo de cooperação financeira e técnica entre o governo norte-americano e a Sudene, alinhavado durante a visita de Furtado a Washington no início de julho de 1961, tornou-se uma prioridade estratégica para o governo Kennedy no âmbito da recém lançada "Aliança para o Progresso" (Furtado, 1997).

Ainda, de acordo com Boianovsky e Monasterio (2017), North veio ao Brasil como visiting professor em missão da Public and Business Administration Division, United States Operation Mission (USOM), a serviço da International Cooperation Administration (ICA), órgão antecessor da United States Agency for International Development (USAID). Furtado, por sua vez, tinha vasta experiência em instituições internacionais e uma visão consolidada sobre os problemas do desenvolvimento econômico. Mesmo sem ser um ministério, a Sudene, concebida e dirigida por Furtado, estava ligada diretamente à Presidência da República e contava com apoio do governo Jânio Quadros. ${ }^{13}$

A última visita de Douglass North ao Brasil ocorreu em 1994, ano seguinte à conquista do Prêmio Nobel de Economia, para o lançamento do seu livro Custos de transação, instituições e desempenho econômico, ocasião em que ministrou palestras no Rio de Janeiro e em São Paulo.

North faleceu em Bezonia, Michigan, no dia 23 de novembro de 2015.

\footnotetext{
12 Sobre o encontro entre Furtado e North, ver: Boianovsky; Monasterio (2017).

${ }^{13}$ Recém-criada, a Sudene tinha um orçamento que equivalia a quase $1 \%$ do total da despesa federal prevista para 1961.
} 


\subsection{Desenvolvimento}

Ao longo das décadas nas quais debruçou-se sobre a análise da historiografia econômica, North distanciou-se progressivamente da Cliometria estabelecendo críticas importantes a elementos dos corpos analíticos do mainstream da teoria econômica ortodoxa, das teorias do crescimento e da teoria do desenvolvimento.

De acordo com North (1994b) a Teoria Neoclássica não consegue explicar com eficiência os motivos que levam as diferentes performances das economias ao longo do tempo. Possui limitações importantes em seus pressupostos como a suposição de que as trocas ocorrem em um mundo sem fricções, sem custos de transação, com os direitos de propriedade perfeitamente especificados e com racionalidade ilimitada, implicando informações fluidas e de conhecimento pleno por parte dos agentes (Robles, 1998; Azevedo, 2015).

Para além das críticas já elencadas em North e Thomas (1973) sobre as tradicionais teorias do crescimento, apontando que estas confundem as consequências do processo com as causas, North $(1981 ; 1990)$ estabelece críticas ao princípio racional e maximizador do homo oeconomicus, afirmando que altruísmo, ideologias, questões éticas, morais, políticas e religiosas possuem papel destacado na motivação do comportamento dos agentes.

Nem mesmo a teoria do desenvolvimento foi poupada de suas críticas. Segundo ele, mesmo depois de quarenta anos de esforços, as disparidades no desempenho das economias e a sua persistência ao longo do tempo não foram satisfatoriamente explicadas, sobretudo devido à omissão em suas análises a respeito da natureza da coordenação e da cooperação humanas (North, 1990).

Essa percepção sobre a inconsistência dada pela teoria aos problemas de coordenação e cooperação humanas levou North, da mesma forma, a questionar o modelo da Teoria dos Jogos que, segundo a sua opinião, não parte de uma hipótese de comportamento humano realista. Em sua perspectiva, o comportamento humano, conforme já destacado, é muito mais complexo do que assume a função de utilidade dos modelos econômicos convencionais (North, 1990).

A partir dessas constatações e partindo da premissa de que o mundo econômico é não ergódico - portanto passivo de mudanças contínuas, inusitadas e atípicas, no qual os agentes precisam de um amplo esforço cognitivo para a compreensão dos fenômenos econômicos e sociais (North, 2005; Lopes, 2013; Azevedo, 2015) -, e, também, com o objetivo de aperfeiçoar o 
instrumental analítico ortodoxo, ${ }^{14}$ North lançou-se no desafio de consolidar uma teoria das instituições e da mudança institucional que lhe permitisse obter melhor resultado na análise da dinâmica do desenvolvimento por meio de uma perspectiva histórica. É, nesse sentido, a partir do livro Instituições, mudança institucional e desempenho econômico, publicado originalmente em língua inglesa no ano de 1990, que o aporte analítico de Douglass North sobre o papel das instituições e da mudança institucional no desenvolvimento econômico alcança maior nível de maturidade.

North inicia o seu discurso por ocasião do recebimento do Prêmio Nobel de Economia, proferido em Estocolmo na Suécia no dia 9 de dezembro de 1993, afirmando (North, 1994b, p. 567):

\begin{abstract}
A história econômica trata sobre o desempenho das economias ao longo do tempo. 0 objetivo das investigações neste campo não é somente permitir que o passado econômico se torne mais claro, mas também contribuir para a teoria econômica proporcionando um marco analítico que nos permita compreender a mudança econômica.
\end{abstract}

Seguindo esse desiderato, o ponto de partida de seu modelo é o axioma de que as instituições e a estrutura produtiva herdadas por meio de processos históricos singulares geram dinâmicas socioeconômicas diversificadas entre nações. Isso significa que o desenvolvimento econômico é um fenômeno eminentemente institucional, resultante de complexas interações entre forças econômicas, políticas e culturais da qual fazem parte distintos arranjos institucionais, que conferem diferenças nas trajetórias de desenvolvimento, bem como na forma de organização das diversas organizações da sociedade. Nesse sentido, o sucesso ou o fracasso das nações decorrem de sua formação histórica e da forma como as suas instituições foram criadas e/ou evoluíram.

Em suma, quando North formula a questão central de sua pesquisa - por que algumas nações adentram em um caminho de prosperidade enquanto outras permanecem na pobreza e na miséria? -, ele encontra a resposta nas instituições e nas organizações que as sociedades construíram ao longo de sua história (North, 1994b). É seguindo essa senda que passamos a apresentar os conceitos fundamentais de sua teoria: instituições, matriz institucional, organizações, dependência de trajetória (path dependence) e ruptura institucional.

As instituições são apresentadas como normas socialmente construídas ("regras do jogo"), gozando de aceitação geral pelos membros de um grupo social, que impõem restrições

\footnotetext{
${ }_{14}$ De acordo com Robles (1998), o modelo analítico desenvolvido por Douglass North é uma modificação da Teoria Neoclássica na medida em que aceita a hipótese fundamental da escassez e as ferramentas da microeconomia ortodoxa, porém, modifica a hipótese de racionalidade ao assumir o pressuposto da informação incompleta e modelos subjetivos da realidade, bem como os retornos crescentes, característico da análise institucionalista.
} 
formais e/ou informais e que moldam o processo de interação, ao mesmo tempo que estruturam incentivos na troca humana, sejam estes de ordem política, social ou econômica. Ao fazerem isso as instituições reduzem a incerteza ${ }^{15}$ na medida em que conferem uma estrutura previsível de ação por meio da coordenação das expectativas divergentes, criando padrões de comportamento duráveis e rotineiros que estabelecem limites para o conjunto de escolhas dos agentes (North, 1990).

As instituições reduzem - juntamente com a tecnologia empregada - os custos de transação e transformação, bem como o de acesso às informações, envolvidos na atividade humana. Porém, em que pese o principal papel das instituições seja o de reduzir a incerteza, estabelecendo uma estrutura estável para a interação humana, estas não são necessariamente eficientes do ponto de vista social, podendo, consequentemente, os custos de transação, produção e acesso as informações diferirem substancialmente entre as sociedades em decorrência de suas diferentes estruturas institucionais.

Existe, assim, um caráter histórico nas trajetórias das sociedades que deriva da forma como as suas matrizes institucionais foram conformadas e evoluíram. Consequentemente, a compreensão das trajetórias de desenvolvimento das nações depende da investigação de sua matriz institucional e, para isso, torna-se necessária a análise da conformação das regras e normas, formais e informais, que a compõem, formando uma rede interligada que, sob variadas combinações, moldam o conjunto de escolhas dos agentes em múltiplos contextos, bem como das instituições que garantem a sua aplicação (enforcement). Essa hipótese leva ao corolário de que, de um lado, o subdesenvolvimento é resultado de instituições socialmente ineficientes e, de outro, somente com uma mudança institucional países subdesenvolvidos conseguiriam romper com a sua trajetória de subdesenvolvimento.

A mudança institucional, ao definir o modo como as sociedades evoluem ao longo do tempo, pode ser até mesmo mais importante para o desenvolvimento, ao estimular o capital físico e humano, do que o acesso a inovações tecnológicas (Gala, 2003; North, 1990). Nessa análise, as organizações - entendidas como grupos de indivíduos unidos por um propósito comum - inserem-se como elementos dinâmicos do modelo. ${ }^{16}$ Ao mesmo tempo que são

\footnotetext{
15 Para North (2018, p. 50): "[...] as incertezas decorrem de incompletude das informações a respeito da conduta dos outros indivíduos no processo de interação humana."

16 De acordo com North (2018), as organizações incluem órgãos políticos (partidos políticos, Câmaras, Senados, Conselhos e agências reguladoras), corpos econômicos (empresas, sindicatos, fazendas, cooperativas e associações patronais), corpos sociais (igrejas, clubes, sociedades filantrópicas e culturais) e órgãos educacionais (escolas, universidades e centros de formação profissional).
} 
influenciadas pelo ambiente institucional na qual estão inseridas, as organizações influenciam a transformação desse ambiente, ao perseguirem os seus objetivos, num processo que molda a evolução institucional da sociedade. Em síntese, se as instituições são as "regras do jogo", as organizações são os jogadores (North, 1990; 1994a; 1994b).

North (1990) ao firmar a compreensão de que as instituições são dependentes de suas trajetórias prévias - portanto "portadoras da história", na medida em que apresentam fortes relações com suas configurações historicamente herdadas - estabelece a matriz institucional de uma sociedade como o elo de ligação entre o passado e o presente, e como condicionante do futuro por meio de uma dependência de trajetória, moldada por meio da interação entre instituições e organizações. Isso realça a importância para a historiografia econômica da compreensão das sequências temporais de eventos e processos sociais, bem como sobre 0 meio em que esses processos ocorreram e que permitiram a geração de determinada percepção pelos indivíduos, constrangendo-os, ou não, a optarem pelo aproveitamento de "janelas de oportunidades" disponíveis. ${ }^{17}$

O conceito de dependência de trajetória surge, assim, como uma explicação que permite observar a influência do passado sobre 0 presente e deste sobre o futuro, possibilitando 0 entendimento das diferenças de desenvolvimento entre países, regiões e cidades, decorrente de processos de autorreforço de suas trajetórias históricas.

Assim, uma vez definido um caminho, há a atuação de mecanismos autorreforçantes que fazem com que a matriz institucional fique "trancada" (lock in) em uma trajetória, mutável apenas por meio de uma ruptura institucional. E, caso ocorra por qualquer motivo uma mudança nas estruturas institucionais, altera-se a percepção por parte dos agentes da matriz de incentivos e incertezas, bem como a predisposição à cooperação e os custos de transação sobre 0 ambiente (North, 2005).

\subsection{Cultura}

A visão analítica de North amadureceu ao longo de vários anos de pesquisas e diversos trabalhos, nos quais ele paulatinamente aperfeiçoou não somente a sua teoria das instituições e

\footnotetext{
17 North (1990) utiliza o conceito de dependência de trajetória para explicar a diferenças socioeconômicas entre os Estados Unidos e a América Latina, posto que o processo de formação institucional distinto entre as colônias americanas acabou por determinar desempenhos econômicos diferentes. Mais à frente entraremos, mesmo que superficialmente, nesse debate.
} 
da mudança institucional, como também o seu entendimento da cultura como chave para a compreensão da dependência de trajetória. ${ }^{18}$

North e Thomas (1973), ao sinalizarem que diferentes processos culturais poderiam resultar em diferentes histórias econômicas, estabeleceram insights que levariam North a paulatinamente ampliar a sua análise sobre a relação entre as instituições informais e 0 desenvolvimento. ${ }^{19} \mathrm{Em}$ que pese isso, a noção de indivíduo assumida em boa parte do livro ainda era muito próxima da perspectiva neoclássica, sendo este ainda visto como um átomo social que estabelecia o seu comportamento de forma independente de seu entorno social (Azevedo, 2015).

Em North (1981) é possível observar uma mudança nessa premissa comportamental dos indivíduos, ${ }^{20}$ sobretudo, com a introdução em sua análise da ideologia, que funcionaria como elemento simplificador dos processos decisórios, conferindo uma visão específica de mundo ao indivíduo tomador de decisão, e servindo como fator explicativo para a compreensão de estruturas políticas e econômicas ineficientes. Ademais, a combinação das regras constitucionais com os códigos de comportamentos culturais subjacentes, ao mesmo tempo em que dá estabilidade às instituições, torna qualquer dinâmica de mudança demorada e, em regra, apenas incremental. Ou seja, ideologia, normas e convenções sociais, bem como códigos de conduta ética e moral, passaram a ser elementos importantes na análise por interferirem na esfera comportamental dos indivíduos e darem legitimidade, estabilidade e ordem à vida social. No limite, sem os constrangimentos impostos por questões ideológicas, os custos de enforcement seriam inviáveis para as organizações.

O livro Instituições, mudança institucional e desempenho econômico, pode ser considerado como o marco temporal que separa o North em amadurecimento teórico (décadas de 1970 e 1980), do North com uma visão teórica mais consolidada e com concatenamentos analíticos mais complexos entre os seus conceitos fundamentais (décadas de 1990 e 2000).

Em North (1990), e alguns trabalhos posteriores, a partir da introdução do conceito de racionalidade limitada, é possível notar significativo avanço na compreensão da dinâmica institucional decorrente do tratamento da cultura como chave para a compreensão da

\footnotetext{
18 Para uma análise mais detalhada da teoria de North, ver: Costa (2019a; 2019b).

19 Um exemplo claro disso é quando North e Thomas (1973) reconhecem a influência de questões religiosas no processo de consolidação do mercado capitalista, citando o problema da condenação dos empréstimos a juros pela Igreja Católica por meio do Papa Clementino V, no século XIV; ao passo que reconhecem o estímulo favorável ao desenvolvimento do capitalismo advindo do cristianismo reformado, citando como exemplo 0 ato de Charles $\mathrm{V}$ (Holanda) que em 1543 liberou o empréstimo com cobrança de juros, segundo os autores, essencial para a dinamização do mercado de capitais holandês.

${ }^{20}$ A teoria da ideologia, inserida por North (1981) em sua análise das instituições, altera a concepção de racionalidade do indivíduo. A este respeito ver Azevedo (2015), em especial o Capítulo 6.
} 
dependência de trajetória. A partir desse ponto, ao invés de proceder a uma análise cronológica de seus trabalhos, optamos - posto entendermos que para efeito de análise e sistematização é mais objetivo e profícuo - por buscar edificar sua visão sobre o papel da cultura no desenvolvimento econômico com base em seus trabalhos mais recentes (décadas de 1990 e 2000).

No conjunto teórico desenvolvido por Douglass North, o mundo econômico é não ergódico, apresentando mudanças contínuas, inusitadas e atípicas, e os indivíduos, por meio de modelos mentais preexistentes, processam informações incompletas, num esforço cognitivo de compreensão dos fenômenos econômicos e sociais, que os auxiliam no entendimento do ambiente ao mesmo tempo em que determinam o seu comportamento social, nem sempre movidos por impulsos maximizadores, mas, em muitos casos, pelo altruísmo e por restrições auto impostas (North, 1990; 2005). Nesse sentido, as instituições - por meio de informações socialmente transmitidas em determinado contexto cultural ${ }^{21}$ - estabelecem mecanismos de incentivos ou restrições nas decisões dos indivíduos e das organizações (North, 1993).

Conforme North (1994b, pp. 572-573):

É necessário desmontar o pressuposto de racionalidade subjacente na teoria econômica para enfocar construtivamente a natureza da aprendizagem humana. A história demonstra que as ideias, as ideologias, os mitos, os dogmas e os preconceitos importam, e uma compreensão da maneira como evoluem é necessária para avançar ainda mais no desenvolvimento de uma estrutura que ajude a explicar a mudança social.

Desta forma, a teoria das instituições e da mudança institucional desenvolvida por North reserva um papel especial para a cultura no processo de determinação das trajetórias sociais de longo prazo na medida em que a estrutura que governa a interação social cotidiana, passando por relações familiares, ou mesmo no campo do trabalho e dos negócios, é definida em grande medida por restrições informais, códigos de conduta, normas de comportamento e convenções. Estes, ao mesmo tempo em que fazem parte de uma herança cultural, definem a forma como os indivíduos processam e utilizam as informações, bem como tomam as suas decisões por meio de seus modelos mentais. Esses modelos mentais - um constructo advindo das ideias, ideologias e religiões - ao sustentarem crenças que reduzem as divergências entre os indivíduos e garantirem a transferência intergeracional do conhecimento, acabam estabelecendo o molde sobre o qual são conformadas as economias e as sociedades (North, 1990; 1993; 2005; North; Denzau, 1994; Lopes, 2013; Azevedo, 2015).

${ }^{21}$ Apesar de trabalhar com a categoria cultura, North, não estabelece uma definição própria dessa categoria. North (1990, p. 37), utiliza-se da definição de Boyd e Richerson (1985, p. 2) que define cultura como a "[...] transmissão de uma geração para a seguinte, por meio do ensino e da imitação de conhecimentos, valores e outros fatores que influenciam o comportamento". 
É em decorrência disso que North (1994b) compreende as instituições como representações da consciência dos indivíduos, expressões dos modelos mentais compartilhados e, portanto, representações externas dos modelos cognitivos individuais, que possuem como finalidade a estruturação e a organização de seu meio através da estabilização das ações e da redução da incerteza.

É nesse sentido que North (2003) destaca que as regras informais acabam se tornando, para a dinâmica das sociedades, até mesmo mais importantes do que as formais. Exatamente por isso, mudanças culturais envolvendo alterações na cosmovisão dos indivíduos, advindas de alterações na ideologia, crenças, valores e religião, abalam a estabilidade das instituições e tendem a ser importantes vetores de mudanças institucionais (North, 1990; 2005; Robles, 1998). ${ }^{22}$

Conforme afirma Robles (1998, p. 16):

North considera que a cultura é a chave para a compreensão do fenômeno da "dependência de trajetória" [path dependence], quer dizer, para compreender por que é tão difícil que as economias uma vez encaminhadas por um caminho de crescimento, ou estagnação, ou declive - logrem reverter sua tendência de longo prazo. North explica que a aprendizagem de qualquer geração está fortemente condicionada pelas percepções derivadas da aprendizagem coletiva secular. Assim, a aprendizagem é um processo cumulativo filtrado pela cultura de uma sociedade.

A cultura, desta forma, torna-se elemento central para explicar a performance econômica e política através do tempo (North, 2005); e, como mencionado, materializa-se, em última instância, como a chave para a dependência de trajetória, na medida em que os indivíduos ao fazerem as suas escolhas o fazem sob influência de suas crenças, formadas por meio de um processo de aprendizagem cumulativo que é transmitido culturalmente de uma geração para outra. Conforme segundo North (1994b, p. 568):

Ou seja, as crenças que os indivíduos, os grupos e as sociedades mantêm e mediante as quais determinam suas opções são uma consequência do aprendizado ao longo do tempo - não somente do lapso de vida de um indivíduo ou de uma geração numa sociedade, mas a aprendizagem incorporada em indivíduos, grupos e sociedades que é cumulativa ao longo do tempo e que passa de geração em geração pela cultura de uma sociedade.

Portanto, o processo de aprendizagem social advém das experiências socioculturais vivenciadas pelos indivíduos, algo que é constantemente atualizado a partir de impulsos externos (North, 2005). Essa visão também está presente em North, Mantzavinos e Shariq (2004) ao enfatizarem que os modelos mentais são dinâmicos e evoluem com o decorrer do tempo como resultado das experiências vivenciadas pelos seres humanos.

22 North (2005) enfatiza que as crenças religiosas e as ideologias seculares desempenham importante papel nas mudanças sociais, citando como exemplo a ascensão e queda do ideal comunista na URSS. 
É, em função disso, que o foco recai, sobretudo, no indivíduo como unidade analítica na medida em que a percepção da realidade social acaba sendo resultante de um processo de aprendizagem e do modelo cognitivo individual, formado em um contexto específico e derivado das crenças e percepções advindas de uma estrutura institucional, ideológica, educacional e religiosa disseminada na sociedade.

Derivado desse entendimento é possível afirmar que: (i) o desempenho econômico de uma sociedade é expressão última de suas instituições, moldadas por um processo histórico através da cultura, das crenças, dos modelos mentais compartilhados e dos modelos cognitivos individuais; (ii) os modelos mentais condicionam as ações dos indivíduos, e acabam determinando trajetórias sociais dependentes; (iii) nenhuma mudança institucional ocorre sem 0 suporte de um sistema de crenças pré-existente; (iv) a determinação causal do desenvolvimento segue, portanto, do nível cognitivo, para o institucional e deste para o econômico (North, 2003; North; Mantzavinos; Shariq, 2004).

\section{Amartya Sen}

\subsection{Síntese biográfica}

Oriundo de uma família hindu, Amartya Kunar Sen nasceu no ano de 1933 em Santiniketan, atual Bangladesh. Após a partição de 1947 emigrou com a família para Bengala Ocidental, onde se formou em Economia em 1953 pelo Presidency College de Calcutá.

Nesse período em Bengala conheceu detalhadamente a história da escassez de alimentos que em 1943 foi responsável pela morte de quase três milhões de pessoas. Esse fato foi determinante para que se tornasse, posteriormente, um ardoroso defensor da promoção do bem-estar.

Prosseguiu seus estudos na Inglaterra, obtendo seu PhD no ano de 1959 pelo Trinity College (Cambridge). Ao longo de sua vida acadêmica fez parte do corpo docente de várias instituições (Jadavpur, Cambridge, Oxford, MIT, Berkeley, Stanford e Cornell). Atualmente é professor de economia e filosofia da cátedra Thomas W. Lamont na Universidade de Harvard.

Em 1998 recebeu o Prêmio Nobel de Economia por seus estudos teóricos na área social e por ter contribuído para uma nova compreensão dos conceitos sobre miséria, fome, pobreza e bem-estar social em regiões pobres, nas quais a principal atividade é a agricultura.

A exemplo de Furtado e North, teve ativo papel em organismos multilaterais; porém, também a exemplo de Furtado, jamais deixou de se preocupar com o destino de sua terra natal, pesquisando e propondo políticas públicas com o objetivo de reduzir as profundas desigualdades 
existentes na Índia. ${ }^{23}$ E, assim como North, teve oportunidade de visitar o Brasil algumas vezes para proferir palestras ou participar de conferências e seminários.

\title{
3.2Desenvolvimento
}

O ponto de partida da análise de Sen sobre o desenvolvimento é a compreensão de que crescimento econômico e desenvolvimento não são necessariamente partes de um mesmo processo. Em que pese o crescimento ser um pressuposto para o desenvolvimento, Sen (2000) alerta que o crescimento não pode se materializar como um fim em si mesmo, ao mesmo tempo em que o desenvolvimento se expressa pela melhoria da qualidade de vida ao lado da liberdade. Conforme Sen (2000, pp. 28-29):

\begin{abstract}
Uma concepção adequada de desenvolvimento deve ir muito além da acumulação de riqueza e do crescimento do Produto Interno Bruto e de outras variáveis relacionadas à renda. Sem desconsiderar a importância do crescimento econômico, precisamos enxergar muito além dele.

Os fins e os meios do desenvolvimento requerem análise e exame minuciosos para uma compreensão mais plena do processo de desenvolvimento; é sem dúvida inadequado adotar como nosso objetivo básico apenas a maximização da renda ou da riqueza, que é, como observou Aristóteles, "meramente útil e em proveito de alguma outra coisa". Pela mesma razão, o crescimento econômico não pode sensatamente ser considerado um fim em si mesmo. 0 desenvolvimento tem de estar relacionado sobretudo com a melhora da vida que levamos e das liberdades que desfrutamos. Expandir as liberdades que temos razão para valorizar não só torna nossa vida mais rica e mais desimpedida, mas também permite que sejamos seres sociais mais completos, pondo em prática nossas volições, interagindo com o mundo em que vivemos e influenciando esse mundo.
\end{abstract}

Se, no que se refere especificamente, à maior abrangência do fenômeno do desenvolvimento em comparação ao do crescimento econômico, Sen não chega a ser propriamente original, uma vez que diversos economistas que se destacaram em meados do século XX - entre os quais Joseph Schumpeter, Charles Kindleberger, Maurice Biè e W. W. Rostow - tiveram a mesma posição; ao enfatizar a importância da liberdade como componente fundamental do desenvolvimento, ele foi bastante original. Em boa parte do livro Desenvolvimento como liberdade, Sen dedica-se à explicação desse aspecto, ilustrado na afirmação: "Ter mais liberdade melhora o potencial das pessoas para cuidar de si mesmas e

\footnotetext{
${ }^{23}$ Vale destacar, nesse particular, o livro Glória incerta: a Índia e suas contradições, escrito em parceria com Jean Drèze, em que argumentam que apesar da aceleração do crescimento da economia indiana nas últimas três décadas, o principal problema do país estaria na falta de atenção que se dedica às necessidades essenciais do povo, especialmente as dos pobres, e muitas vezes das mulheres. Sen e Drèze (2015) reconhecem que houve grandes fracassos tanto na promoção de um crescimento participativo como na aplicação dos recursos públicos gerados pelo crescimento econômico para melhorar a condição de vida das pessoas. Oferecem, a partir dessa constatação, uma análise poderosa das carências e desigualdades da Índia, indicando, com uma compreensão mais clara da gravidade das privações humanas no país, as possibilidades de mudanças que seriam permitidas por uma prática democrática.
} 
para influenciar o mundo, questões centrais para o processo de desenvolvimento" (Sen, 2000, p. 33).

Logo no Prefácio, ao fazer considerações sobre, de um lado, um mundo com níveis de opulência sem precedentes e, de outro, um mundo de privação, destituição e opressão extraordinárias, Sen $(2000$, p. 10) destaca a estreita relação entre liberdade e desenvolvimento:

A expansão da liberdade é vista, por essa abordagem, como o principal fim e o principal meio do desenvolvimento. $O$ desenvolvimento consiste na eliminação de privações de liberdade que limitam as escolhas e as oportunidades das pessoas de exercer ponderadamente sua condição de agente. A eliminação de privações de liberdades substanciais é constitutiva do desenvolvimento. Porém, para uma compreensão mais plena da relação entre desenvolvimento e liberdade, precisamos ir além desse reconhecimento básico (ainda que crucial). A importância intrínseca da liberdade humana em geral, como o objetivo supremo do desenvolvimento, é acentuadamente suplementada pela eficácia instrumental de liberdades específicas na promoção de liberdades de outros tipos.

A respeito desses encadeamentos, Sen $(2000$, p. 10) prossegue:

Os encadeamentos entre diferentes formas de liberdade são empíricos e causais, e não constitutivos e compositivos. Por exemplo, há fortes indícios de que as liberdades econômicas e políticas se reforçam mutuamente, em vez de serem contrárias umas às outras (como às vezes se pensa). Analogamente, oportunidades sociais de educação e assistência médica, que podem requerer a ação pública, complementam oportunidades individuais de participação econômica e política e também favorecem nossas iniciativas para vencer privações. Se o ponto de partida da abordagem é identificar a liberdade como o principal objetivo do desenvolvimento, 0 alcance da análise de políticas depende de estabelecer os encadeamentos empíricos que tornam coerente e convincente 0 ponto de vista da liberdade como a perspectiva norteadora do processo de desenvolvimento.

Dessa forma, o caminho para o desenvolvimento para Sen (2000) perpassa pela superação dos problemas com a privação, destruição e opressão, que envolvem a pobreza, insegurança alimentar, violação de liberdades políticas elementares e liberdades formais básicas, ameaças ao meio ambiente e à sustentabilidade econômica e social. Ou seja, o desenvolvimento é no limite a expansão das liberdades reais que os indivíduos desfrutam integrando considerações econômicas, sociais e políticas. ${ }^{24}$ Conforme Sen (2000, p. 10):

[...] a condição de agente dos indivíduos é, em última análise, central para lidar com essas privações. Por outro lado, a condição de agente de cada um é inescapavelmente restrita e limitada pelas oportunidades sociais, políticas e econômicas de que dispomos. Existe uma acentuada complementariedade entre a condição de agente individual e as disposições sociais: é importante o reconhecimento simultâneo da centralidade da liberdade individual e da força das influências sociais sobre 0 grau e 0 alcance da liberdade individual. Para combater os problemas que enfrentamos, temos de considerar a liberdade individual um comprometimento social.

\footnotetext{
24 Sen (2000, p. 17): "Mas as liberdades dependem também de outros determinantes, como as disposições sociais e econômicas (por exemplo, os serviços de educação e saúde) e os direitos civis (por exemplo, a liberdade de participar de discussões e averiguações públicas."
} 
Isto posto, o autor enfatiza que algumas liberdades instrumentais, conforme Tabela 1, são fundamentais e estão inter-relacionadas.

\section{Tabela 1 - Liberdades instrumentais fundamentais}

\begin{tabular}{|l|l|}
\hline Liberdades políticas & $\begin{array}{l}\text { Oportunidades que as pessoas têm para determinar quem deve governar e com } \\
\text { base em que princípios. Inclui a possiblidade de fiscalizar e de criticar } \\
\text { autoridades, de ter liberdade de expressão, liberdade de imprensa, pluralismo } \\
\text { partidário, liberdade de voto etc. Em síntese, são dos direitos políticos } \\
\text { associados às democracias. }\end{array}$ \\
\hline Oportunidades econômicas & $\begin{array}{l}\text { Oportunidades que os indivíduos têm para utilizar recursos econômicos com } \\
\text { propósitos de consumo, produção ou troca. Pressupõe liberdade de mercado. }\end{array}$ \\
\hline Oportunidades sociais & $\begin{array}{l}\text { São as disposições que a sociedade estabelece nas áreas sociais, com } \\
\text { destaque para saúde e educação, as quais influenciam as liberdades } \\
\text { substantivas de o indivíduo viver melhor. Estão na base, também, para que o } \\
\text { indivíduo tenha uma participação mais efetiva em atividades econômicas e } \\
\text { políticas. }\end{array}$ \\
\hline Garantias de transparência & $\begin{array}{l}\text { Referem-se às necessidades de sinceridade que as pessoas podem esperar: a } \\
\text { liberdade de lidar uns com os outros sob garantias de dessegredo e clareza. } \\
\text { São inibidoras da corrupção, da irresponsabilidade financeira e de transações } \\
\text { ilícitas. }\end{array}$ \\
\hline Segurança protetora & $\begin{array}{l}\text { Necessária para proporcionar uma rede de segurança social, capaz de proteger } \\
\text { a população afetada seja reduzida à miséria abjeta, ou até mesmo a fome e a } \\
\text { morte. }\end{array}$ \\
\hline
\end{tabular}

Fonte: Elaboração própria a partir de Sen (2000).

Ainda em sua análise dos condicionantes econômicos relacionados ao desenvolvimento e à liberdade, Sen (2000, pp. 22-23) dá especial destaque ao papel dos mercados, afirmando:

A capacidade do mecanismo de mercado de contribuir para o elevado crescimento econômico e o progresso econômico global tem sido ampla e acertadamente reconhecida na literatura contemporânea sobre desenvolvimento. No entanto, seria um erro ver o mecanismo de mercado apenas como um derivativo. Como observou Adam Smith, a liberdade de troca e transação é ela própria uma parte essencial das liberdades básicas que as pessoas têm razão para valorizar.

Complementando o exame da importância dos mercados, pondera Sen (2000, p. 23):

Ser genericamente contra os mercados seria quase tão estapafúrdio quanto ser genericamente contra a conversa entre as pessoas (ainda que certas conversas sejam claramente infames e causem problemas a terceiros - ou até mesmo aos próprios interlocutores). A liberdade de trocar palavras, bens ou presentes não necessita de justificação defensiva com relação a seus efeitos favoráveis mas distantes; essas trocas fazem parte do modo como os seres humanos vivem e interagem na sociedade (a menos que sejam impedidos por regulamentação ou decreto). A contribuição do mecanismo de mercado para o crescimento econômico é obviamente importante, mas vem depois do reconhecimento da importância direta da liberdade de troca - de palavras, bens, presentes.

Sen, desta forma, contribuiu para o debate contemporâneo do desenvolvimento ao destacar a liberdade como elemento fundamental para o desenvolvimento. Contudo, a sua influência nesse campo não se limitou somente ao plano teórico, uma vez que, juntamente com Mahbub ul Hak, foi idealizador, em 1989, do Índice de Desenvolvimento Humano IDH (Índice de Desenvolvimento Humano), um indicador que passou a ser utilizado no mundo todo como a 
principal referência para definir o grau de desenvolvimento de um país. Tal indicador, mais amplo, do que os até então utilizados (sobretudo PIB e PIB per capita), considera três variáveis para efeito de cálculo: o nível de renda, a educação (captada através da taxa de alfabetização e da taxa de matrícula nos três níveis de ensino), e a saúde (captada pela esperança de vida).

\subsection{Cultura}

A exemplo de Furtado e North, Sen revelou desde seus primeiros trabalhos que sua visão da economia extrapolava muito os limites da ciência econômica stricto senso. Os três, portanto, dão razão à convicção de John Stuart Mill, endossada posteriormente por Alfred Marshall, segundo a qual "não será provavelmente um bom economista quem não é nada mais do que isso".

Essa visão estendida da análise do desenvolvimento, na qual se constata a forte relação da economia com outras áreas do conhecimento, percebida em Sen (1999) e reforçada em Sen (2000), estabelece relevantes vínculos da economia (e do desenvolvimento em especial), com fatores como liberdade, justiça, democracia, oportunidade social, demografia, ética, direitos humanos, escolha social, instituições, meio ambiente e comprometimento social.

No específico às questões atinentes à cultura, e se, historicamente, essa associação entre cultura e economia sempre esteve no centro das atenções de Sen, observa-se uma importante mudança de foco na evolução de seu pensamento e de suas obras; de abrangência local e/ou regional, foi ganhando abrangência cada vez maior à medida que a globalização e a interdependência entre as nações tornaram-se uma das características mais marcantes da realidade contemporânea.

Exemplo dessa mudança de foco pode ser identificada na acentuada preocupação com os problemas da Índia e da região nos escritos iniciais, que, sem jamais ser abandonada, vai cedendo espaço a preocupações de maior abrangência, ganhando crescente destaque as relações entre Ocidente e Oriente, nas quais, muito além do distanciamento referente ao desenvolvimento, merecem destaque os aspectos relacionados à cultura, à religião, à filosofia, à liberdade política e à maior ou menor influência da democracia. Para Sen (2000, p. 267):

Culturas e tradições sobrepõem-se em regiões como o Leste Asiático e mesmo em países como Japão, China ou Coreia, e as tentativas de generalização sobre os "valores asiáticos" (com implicações substanciais - e frequentemente brutais - para multidões de pessoas nessa região com diversas fés, convicções e comprometimentos) só podem ser extremamente grosseiras. Mesmo os 2,8 milhões de habitantes de Cingapura apresentam grandes contrastes em suas tradições culturais e históricas. 
Neste ponto, convém destacar o caráter altamente oportuno da análise de Sen no que se refere às divergências entre Ocidente e Oriente, uma vez que as sequelas do atentado às torres gêmeas em Nova York e da reação militarizada protagonizada pelos Estados Unidos deixaram como herança uma preocupação permanente, que eventualmente assume picos de tensão. ${ }^{25}$ Nesses momentos, de agravamento do clima de tensão, ganha ainda mais validade as observações de Sen a respeito da dificuldade encontrada na maior parte dos países ocidentais, fundamentada na cosmovisão judaico-cristã, de entender a cultura e a forma de pensar predominantes no Oriente. Conforme Sen (2000, p. 267):

As linhas de raciocínio autoritárias presentes na Ásia - e, de um modo mais geral, em sociedades não-ocidentais - muitas vezes são corroboradas indiretamente por modos de pensar encontrados no próprio Ocidente. Existe claramente uma tendência nos Estados Unidos e na Europa de supor, ao menos implicitamente, a primazia da liberdade política e da democracia como uma característica fundamental e muito antiga da cultura ocidental - característica difícil de ser encontrada na Ásia. Seria, por assim dizer, um contraste entre o autoritarismo alegadamente implícito - digamos, no confucionismo - e o respeito pela liberdade e pela autonomia individuais que se afirma estar fortemente arraigado na cultura liberal ocidental. Os ocidentais que se empenham pela liberdade pessoal e política no mundo não-ocidental comumente julgam estar levando valores ocidentais para a Ásia e a África. O mundo é convidado a entrar para o clube da "democracia ocidental" e admirar e defender os "valores ocidentais" tradicionais.

Essa tentativa de não apenas considerar, mas de impor os valores predominantes no Ocidente por parte de relevantes lideranças políticas da atualidade é, seguramente, um dos principais motivos do clima de tensão observado em várias partes do mundo.

Finalmente, muito provavelmente influenciado pelo aporte teórico desenvolvido pelos neoinstitucionalistas, dentre eles o próprio North, Sen (2000) menciona a importância das instituições para o processo de desenvolvimento. Para ele a análise da dinâmica do capitalismo precisa superar a visão unívoca da maximização de lucros e incorporar elementos éticos que envolvem valores e normas. ${ }^{26}$ Assim, o funcionamento bem-sucedido dos mercados, em parte, se deve ao que ele chama de um "sólido alicerce de instituições". Conforme Sen (2000, p. 298):

O funcionamento de mercados bem-sucedidos deve-se não só ao fato da trocas serem "permitidas", mas também ao sólido alicerce de instituições (como por exemplo estruturas legais eficazes que

\footnotetext{
25 Um exemplo disso foi a morte do major-general Qassen Soleimani, no início de 2020, considerado a segunda pessoa mais poderosa do Irã, num ataque aéreo dos Estados Unidos em um aeroporto de Bagdá.

${ }^{26}$ Conforme Sen (2000, p. 298): "Embora o capitalismo com frequência seja visto como um sistema que só funciona com base na ganância de todos, o funcionamento eficiente da economia capitalista depende, na verdade, de poderosos sistemas de valores e normas. Com efeito, conceber o capitalismo como dada mais do que um sistema baseado em um conglomerado de comportamento ganancioso é subestimar imensamente a ética do capitalismo, que contribuiu enormemente para suas formidáveis realizações."
} 
defendem os direitos resultantes de contratos) e da ética de comportamento (que viabiliza os contratos negociados sem a necessidade de litígios constantes para obter o cumprimento do que foi contratado). O desenvolvimento e o uso da confiança na palavra e na promessa das partes envolvidas podem ser um ingrediente importantíssimo para o êxito de um mercado.

Em síntese, para Sen (2000), as normas explícitas e implícitas criam as condições para a existência da confiança mútua, condição necessária para o funcionamento adequado de uma economia de troca, numa análise que se aproxima bastante da que fora desenvolvida por North (1990).

\section{Considerações finais}

A escolha destes três autores não foi aleatória, contudo, apesar de pertencerem a escolas de pensamento diferentes, surpreendentemente as suas análises apresentam pontos de convergência e complementariedades que são fundamentais para qualificar 0 debate contemporâneo acerca das perspectivas do desenvolvimento ou superação das condições de subdesenvolvimento.

Assim, esperamos ter conseguido - neste ano em que se faz o memorial do pensamento de Celso Furtado e de Douglass North (que se vivos estivessem completariam 100 anos) mostrar alguns pontos de convergência do pensamento e da ação destes três baluartes da história do pensamento econômico, notadamente no que se refere a três aspectos: (i) uma visão econômica que vai muito além do economicismo tão presente em muitas análises; (ii) a constante preocupação com a busca permanente de melhores padrões de vida para as populações em geral e, em especial, para as populações de países subdesenvolvidos; e; (iii) 0 estreito vínculo entre cultura, instituições e desenvolvimento.

Como pôde ser percebido na leitura, julgamos oportuno fazer, antes do compêndio teórico de cada autor, breves registros biográficos; e, nos casos de Furtado e Sen, resta patente que as suas infâncias e juventudes vividas em regiões subdesenvolvidas acabaram por trazer forte influência sobre as suas reflexões analíticas.

Contudo, apesar de avanços relevantes em termos de políticas de desenvolvimento, os dois autores vindos de países subdesenvolvidos em determinado momento manifestaram muitas dúvidas quanto aos resultados alcançados em seus respectivos países. Isto fica evidente em Brasil: a construção interrompida, em que Furtado (1992) lamenta as frequentes descontinuidades nos raros planos de desenvolvimento efetivamente levados a cabo no Brasil, e Glória incerta, no qual Drèze e Sen (2015) chamam a atenção para as enormes desigualdades ainda existentes e que se constituem em enormes desafios para o efetivo desenvolvimento da Índia. 
Por último, os três autores, com maior ou menor ênfase, ressaltam que a cultura é um elemento estratégico e determinante para a análise do desenvolvimento e/ou subdesenvolvimento. E, quando Furtado menciona que o entendimento do comportamento dos agentes econômicos somente é possível através da análise de como estão arquitetadas as suas estruturas sociais, acaba estabelecendo uma possível ponte com a teoria das instituições desenvolvida por North e apropriada, mesmo que parcialmente, por Sen.

\section{Bibliografia}

AZEVEDO, Bonnie. Uma análise antropológica de Douglass North (1973-2009): indivíduo, racionalidade, cultura e instituições. Tese (Doutorado em Políticas Públicas, Estratégias e Desenvolvimento) - Programa de Pós-Graduação em Políticas Públicas, Estratégias e Desenvolvimento, Instituto de Economia, Universidade Federal do Rio de Janeiro (UFRJ), Rio de Janeiro, 2015.

BOIAVOVSKY, Mauro; MONASTERIO, Leonardo. O Encontro entre Douglass North e Celso Furtado em 1961: visões alternativas sobre a economia nordestina. Texto para discussão. Brasília: Rio de Janeiro: Ipea, 2017.

BOYD, R.; RICHERSON, P.J. Culture and the evolutionary process. Chicago: University of Chicago Press, 1985.

BRANDÃO, Gildo Marçal. O peregrino da ordem do desenvolvimento. In.: LIMA, Marcos Costa; DAVID, Maurício Dias (orgs.). A atualidade do pensamento de Celso Furtado. São Paulo: Francis, 2008.

CHRISTENSEN, Clayton M. O dilema da inovação. Tradução de Edna Emi Onoe Veiga. São Paulo: Makron Books, 2001.

COSTA, Eduardo José Monteiro da. Teoria das Instituições e da Mudança Institucional de Douglass North: Cultura, Estado e Dependência de Trajetória. CADERNOS CEPEC, v. 8, p. 6483, 2019a.

COSTA, Eduardo José Monteiro da. A cultura como chave para a dependência da trajetória na teoria institucionalista de Douglas North. Revista Nova Economia, v.29, Número Especial, p.1359-1385, 2019b.

DRĖZE, Jean; SEN, Amartya. Glória incerta: a Índia e suas contradições. Tradução de Ricardo Doninelli Mendes e Laila Coutinho. São Paulo: Companhia das Letras, 2015.

FURTADO, Celso. Pequena introdução ao desenvolvimento. 1. ed. São Paulo: Nacional, 1980.

FURTADO, Celso. "Autorretrato intelectual". In.: FURTADO, C. Celso Furtado. São Paulo: Ática, 1983.

FURTADO, Celso. Cultura e desenvolvimento em época de crise. 2. ed. Rio de Janeiro: Paz e Terra, 1984.

FURTADO, Celso. Brasil: a construção interrompida. 1. ed. Rio de Janeiro: Paz e Terra, 1992a.

FURTADO, Celso. O subdesenvolvimento revisitado. Revista Economia e Sociedade. Instituto de Economia UNICAMP, v. 1, p. 5-19, 1992 b.

FURTADO, Celso. Obra autobiográfica de Celso Furtado: aventuras de um economista brasileiro e a Fantasia Desfeita. Tomo II. Rio de Janeiro: Paz e Terra, 1997.

FURTADO, Celso. O capitalismo global. 1. ed. São Paulo: Paz e Terra, 1998.

FURTADO, Celso. Criatividade e dependência na civilização industrial. São Paulo: Companhia das Letras, 2008. 
GALA, Paulo. A teoria institucional de Douglass North. Revista de Economia Política, v. 23, n. 2 (90), abr.-jun. 2003.

LOPES, Herton Castiglioni. Instituições e crescimento econômico: os modelos teóricos de Thorstein Veblen e Douglass North. Revista de Economia Política. vol.33 no.4 São Paulo Oct./Dec. 2013. Disponivel em: <www.scielo.br/scielo.php?pid=S010131572013000400004\&script=sci_arttext>. Acesso em: 22 de Março de 2019.

NORTH, Douglass C. Structure and Change in Economic History. New York: W.W. Norton, 1981.

NORTH, Douglass C. Institutions, institutional change, and economic performance - political economy of institutions and decisions. Cambridge: Cambridge University Press, 1990.

NORTH, Douglass C. Five Propositions about institutional change. Munich: University Library of Munich, 1993. Disponível em: https://ideas.repec.org/p/wpa/wuwpeh/9309001.html. Acesso em 12 de abril de 2019.

NORTH, Douglass C. Custos de transação, instituições e desempenho econômico. Tradução de Elizabete Hart. Rio de Janeiro: Instituto Liberal, 1994a.

NORTH, Douglass C. El desempeño económico a lo largo del tiempo. El Trimestre Económico, v. LXI (4), edição 244, 567-583, 1994b.

NORTH, Douglass C. The Role of Institutions in Economic Development: Gunnar Myrdal Lecture. United Nations Publications, 2003.

NORTH, Douglass C. Understanding the process of economic change. Princeton/Oxford: Princeton University Press, 2005.

NORTH, Douglass C. Instituições, mudança institucional e desempenho econômico. Tradução de Alexandre Morales. São Paulo: Três Estrelas, 2018.

NORTH, Douglass; THOMAS, Robert. The Rise of the Western Word: A New Economic History. Cambridge: Cambridge University Press, 1973.

NORTH, Douglass; DENZAU, Arthur. Shared mental models: ideologies and institutions. Center for Politics and Economics Claremont Graduate School and Center for the Study of Political Economy. Washington University (St. Louis), 1994. Disponível em http://ecsocman.hse.ru/data/957/750/1216/9309003.pdf. Acesso 13 de abril de 2019.

NORTH, D.; MANTZAVINOS, C.; SHARIQ, S. Learning, institutions, and economic performance. Perspectives on politics. Vol. 2. $N^{0}$ 1. P. 1-19, 2004. Disponível em: https://philarchive.org/archive/MANLIA-3. Acesso em 12 de abril de 2019.

Plano da Secretaria da Economia Criativa: políticas, diretrizes e ações, 2011-2014. Brasília, Ministério da Cultura, 2011.

PORTER, Michael. A vantagem competitiva das nações. Tradução de Waltensir Dutra. Rio de Janeiro: Elsevier, 1989.

ROBLES, Gustavo A. Prado. El Pensamiento Económico de Douglass C. North. Laissez-Faire, No. 9, 13-32, Sept., 1998.

SEN, Amartya. Sobre ética e economia. Tradução de Laura Teixeira Motta; revisão técnica de Ricardo Doninelli Mendes. São Paulo: Companhia das Letras, 1999.

SEN, Amartya. Desenvolvimento como liberdade. Tradução de Laura Teixeira Motta; revisão técnica de Ricardo Doninelli Mendes. São Paulo: Companhia das Letras, 2000.

SILVA, Ana Paula Londe; BARROS, Laura Diniz Penteado de. Cultura e desenvolvimento: um estudo da perspectiva de Celso Furtado. Revista Multiface, Belo Horizonte, vol. 2, 2014. Disponível em https://revistas.face.ufmg.br/index.php/multiface/article/view/3082. Acesso em 16 de janeiro de 2020. 


\section{Resumo}

Este artigo tem por objetivo apresentar alguns pontos de convergência do pensamento e da ação três baluartes da história do pensamento econômico, Celso Furtado, Douglass North e Amartya Sen, notadamente no que se refere a: (i) uma visão econômica que vai muito além do economicismo tão presente em muitas análises econômicas; (ii) a constante preocupação com a busca permanente de melhores padrões de vida para as populações em geral e, em especial, para as populações de países subdesenvolvidos; e; (iii) 0 estreito vínculo entre cultura e desenvolvimento.

Palavras-Chaves: Celso Furtado; Douglass North; Amartya Sen; cultura; desenvolvimento.

\section{Abstract}

This article aims to present some points of convergence of thought and action, three bastions of the history of economic thought, Celso Furtado, Douglass North and Amartya Sen, notably with regard to: (i) an economic vision that goes far beyond economism so present in many economic analyzes; (ii) the constant concern with the permanent search for better living standards for the population in general and, in particular, for the populations of underdeveloped countries; and; (iii) the close link between culture and development.

Keywords: Celso Furtado; Douglass North; Amartya Sen; culture; development. 